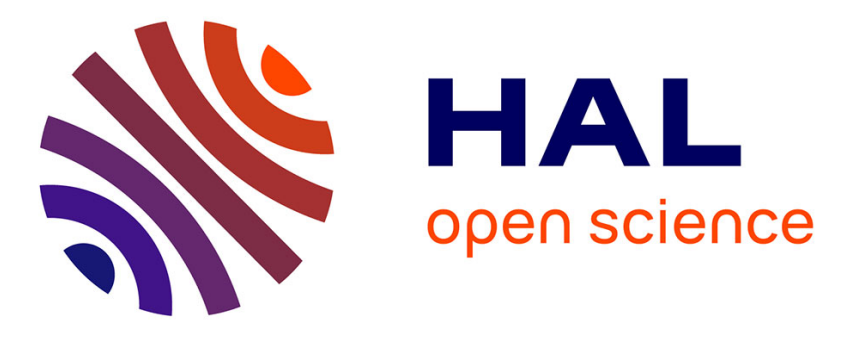

\title{
Pushing the Boundaries of Participatory Design
}

Jessica Korte, Aurora Constantin, Cristina Adriana Alexandru, Jerry Alan Fails, Eva Eriksson, Judith Good, Helen Pain, Juan Pablo Hourcade, Franca Garzotto, Annalu Waller

\section{- To cite this version:}

Jessica Korte, Aurora Constantin, Cristina Adriana Alexandru, Jerry Alan Fails, Eva Eriksson, et al.. Pushing the Boundaries of Participatory Design. 17th IFIP Conference on Human-Computer Interaction (INTERACT), Sep 2019, Paphos, Cyprus. pp.747-753, 10.1007/978-3-030-29390-1_74 . hal-02878622

\section{HAL Id: hal-02878622 \\ https://hal.inria.fr/hal-02878622}

Submitted on 23 Jun 2020

HAL is a multi-disciplinary open access archive for the deposit and dissemination of scientific research documents, whether they are published or not. The documents may come from teaching and research institutions in France or abroad, or from public or private research centers.
L'archive ouverte pluridisciplinaire HAL, est destinée au dépôt et à la diffusion de documents scientifiques de niveau recherche, publiés ou non, émanant des établissements d'enseignement et de recherche français ou étrangers, des laboratoires publics ou privés.

\section{(c)(1)}

Distributed under a Creative Commons Attribution| 4.0 International License 


\title{
Pushing the Boundaries of Participatory Design
}

\author{
Jessica Korte ${ }^{1[0000-0002-4412-7199]}$, Aurora Constantin ${ }^{2[0000-0001-5352-5300]}$, \\ Cristina Adriana Alexandru ${ }^{1}$, Jerry Alan Fails ${ }^{3[0000-0001-6139-1162]}$, Eva \\ Eriksson $^{4,5}[0000-0002-1013-6222]$, Judith Good ${ }^{6}$, Helen \\ Pain ${ }^{10000-0002-1812-1324]}$, Juan Pablo Hourcade ${ }^{7}$, Franca Garzotto ${ }^{8}$, and \\ Annalu Waller 9 [0000-0002-3009-8040] \\ 1 The University of Queensland, Brisbane, Australia j.korte@uq.edu.au \\ 2 The University of Edinburgh, Edinburgh, UK \\ \{aurora.constantin, cristina.alexandru, helen.pain\}@ed.ac.uk \\ 3 Boise State University, Boise, Idaho V6M 22P, USA jerryfails@boisestate.edu \\ 4 Aarhus University, Aarhus, Denmark evae@cc.au.dk \\ ${ }^{5}$ Chalmers University of Technology, Gothenburg, Sweden \\ 6 University of Sussex, Brighton, UK j.good@sussex.ac.uk \\ 7 University of Iowa, Iowa City, Iowa 52242, USA juanpablo-hourcade@uiowa.edu \\ 8 Politecnico di Milano, Milan, Italy franca.garzotto@polimi.it \\ 9 University of Dundee, Dundee, UK a.waller@dundee.ac.uk
}

\begin{abstract}
Participatory Design (PD) is a design approach which aims to support users to contribute as partners throughout the entire design process of a product or service intended for their use. PD researchers are interested in employing and/or developing methods and techniques that maximise users' contributions. By accommodating specific populations, PD proved to offer unique benefits when designing technology for "fringe" groups. However, a lack of understanding of the appropriateness of existing approaches across groups and contexts presents a challenge for the PD community. This workshop will encourage discussion around this challenge. The participants will have the opportunity to exchange and reflect on their experiences with using PD with "fringe" groups. Moreover, we aim to identify, synthesise and collate PD best practices across contexts and participant groups.
\end{abstract}

Keywords: Participatory Design $\cdot$ PD · co-design · marginalised · disempowered $\cdot$ fringe $\cdot$ methodology $\cdot$ best practice $\cdot$ reflection

\section{Background and Themes}

Participatory design (PD) has expanded from workplace democratisation [9] to non-work settings [4] and to "fringe" groups who lack social power for a variety of reasons (e.g. age, disability, culture). This includes children $[7,10]$, older adults [25], people with cognitive impairments such as dementia [26], neurodiverse people [21], people with motor impairments [16], people with visual impairments [32], Deaf ${ }^{10}$ people [18], and people with communication difficulties [6].

${ }^{10}$ Capitalised "Deaf" refers to people who identify as culturally Deaf, belonging to the Deaf community and usually using a sign language to communicate. 
PD can provide unique benefits in designing technology for "fringe" groups, including deeper understandings of users and contexts of use, leading to products which better fit their purpose $[10,13]$, increased ownership $[8,19]$ and adoption of technology [1,23], and higher user satisfaction [2,27]. Involvement in PD can create opportunities for some user groups (e.g. children) to develop increased self-esteem and confidence $[15,17,20]$, and collaborative, communication and problem solving skills $[15,17]$. PD has been shown to enhance lives $[31,5]$, and alter social attitudes [22].

PD with new user groups brings specific needs and challenges [12]. Some groups (e.g. children, minority cultures, people with a disability) require particular accommodations, or the creation or adaption of $\mathrm{PD}$ approaches to empower them to express their ideas $[25,28,11,21]$ and maximise their contribution to design $[3,14,24]$; however the PD community faces a challenge in identifying the appropriateness of existing tools to new contexts and user groups $[29,6,30]$.

\section{Objectives, Target Audience and Expected Outcomes}

This workshop aims to address two challenges identified by Vines et al. [30]:

- "Working as a community to identify the aspects of diverse participatory processes... that can support 'best practice' across multiple domains and contexts" and

- "Providing greater emphasis in literature to participant experience and researcher self-reflection...." (p. 5)

To this end, PD researchers will be engaged in a PD activity: adapting PD methods used with particular "fringe" groups to other contexts and user groups.

There are two target audiences for this workshop: 1) researchers who have created or adapted PD approaches for a specific "fringe" group, and 2) researchers who have undertaken PD with "fringe" groups. Prospective participants are invited to submit position papers describing their creation, adaptation and/or use of PD methods, techniques or tools with particular "fringe" groups, providing details of context of use, procedure, results, challenges and lessons learned. Within the workshop, a subset of novel or adapted PD approaches will be selected to be adapted once more to new contexts, based on reflection on other participants' experiences working with different "fringe" groups. This will result in a series of newly adapted PD approaches, which will be reported at INTERACT.

The workshop organisers will contact an HCI journal (e.g. TOCHI or International Journal for Human-Computer Studies) to discuss the possibility of editing a special issue entitled Pushing the Boundaries of Participatory Design, which will publish extended versions of the participants' position papers, as well summary reports of the newly adapted PD approaches.

\section{Organisers}

Jessica Korte (Co-chair) is a Postdoctoral Academic in The University of Queensland's Co-Innovation Group, Australia. She is passionate about PD's po- 
tential to empower "fringe" groups. She developed a PD approach for designing with young Deaf children. She hopes to work with Deaf and Indigenous communities to design language resources, language robots, and learning activities.

Aurora Constantin (Co-chair) is a University Teacher and postdoctoral researcher at the University of Edinburgh School of Informatics, UK. Her research focuses on designing technology for individuals with Autism Spectrum Disorder, PD, User-Centred Design, and Action Research with various stakeholders. Currently she is working on designing a tool to support children with ASD to express their creativity during PD. She leads the CISA HCI group.

Cristina Adriana Alexandru (Co-chair) is a Research Associate and University Teacher at the University of Edinburgh School of Informatics, UK. She specialises in UCD, development, and usability evaluation of healthcare systems and tools to cater for the needs of different healthcare practitioners. She has interests in PD and consideration of the viewpoints of very different user groups, and automating usability evaluation of user interfaces in healthcare.

Jerry Alan Fails is an Associate Professor in the Computer Science Department at Boise State University in Idaho, USA. He has designed technologies with and for children using PD methods for 15 years. His primary area of research is HCI, with a focus on technologies that engage children with one another, get them active, and encourage them to explore the world around them.

Judith Good is Professor of Interaction Design and Inclusion in the Department of Informatics, University of Sussex, UK. Her research interests focus on PD of new technologies for children, with and without disabilities, and developing new participatory methodologies for typically marginalised populations to have greater involvement in design and evaluation of new technologies.

Eva Eriksson is an Assistant professor at the School of Communication and Culture, Department of Information Studies at Aarhus University, Denmark, and a senior lecturer at Chalmers University of Technology, Sweden. Her research focus is interaction design in public knowledge institutions, specializing in PD with developmentally diverse children.

Helen Pain is Professor of Interactive Learning Environments at the University of Edinburgh School of Informatics/Design Informatics. Her research in Interaction Design uses PD approaches to develop support for learning and communication (particularly social communication and affect) in children with special needs, using technology to support play and exploration.

Juan Pablo Hourcade is an Associate Professor at the University of Iowa's Department of Computer Science, USA. He has performed extensive research in the development of technologies for diverse user groups, including children, people with ASD and older adults. He is the author of the first comprehensive book on the topic of child-computer interaction, and is on the Editorial Board of the International Journal of Child-Computer Interaction.

Franca Garzotto is Professor of Information Engineering at Politecnico di Milano, Italy, where she leads the Innovative Interactive Interfaces Laboratory (i3lab). The lab focuses on advanced interactive technologies (Wearable Virtual and Augmented Reality, Social Robots, Smart Objects and Smart Spaces, Emo- 
tional Conversational Agents) for people with cognitive disability, particularly children, and works in strong collaboration with specialized therapeutic and educational institutions in Italy and Europe. Together with these persons and their caregivers, we co-design and create innovative tools and services that aim at providing new forms of interventions at school, home, and care centre.

Annalu Waller is a Personal Chair in Human Communication Technologies. She directs the Dundee Augmentative and Alternative Communication Research Group. Her primary research areas are HCI, natural language processing, personal narrative and assistive technology. In particular, she focuses on empowering end users, including disabled adults and children, by involving them in the design and use of technology.

\section{References}

1. Albouys-Perrois, J., Laviole, J., Briant, C., Brock, A., Brock, A.M.: Towards a multisensory augmented reality map for blind and low vision people: A participatory design approach (2018), https://hal-enac.archives-ouvertes.fr/hal-01801116

2. Bano, M., Zowghi, D.: A systematic review on the relationship between user involvement and system success. Information and Software Technology 58, 148-169 (2015)

3. Benton, L., Johnson, H., Ashwin, E., Brosnan, M., Grawemeyer, B.: Developing ideas: Supporting children with autism within a participatory design team. In: Proceedings of the SIGCHI Conference on $\mathrm{Hu}-$ man Factors in Computing Systems. pp. 2599-2608. CHI '12, ACM, New York, NY, USA (2012). https://doi.org/10.1145/2207676.2208650, http://doi.acm.org/10.1145/2207676.2208650

4. Björgvinsson, E., Ehn, P., Hillgren, P.A.: Participatory design and "democratizing innovation". In: Proceedings of the 11th Biennial Participatory Design Conference. pp. 41-50. PDC '10, ACM, New York, NY, USA (2010). https://doi.org/10.1145/1900441.1900448, http://doi.acm.org/10.1145/1900441.1900448

5. Carroll, J.M., Rosson, M.B.: Participatory design in community informatics. Design Studies 28(3), 243 - 261 (2007). https://doi.org/https://doi.org/10.1016/j.destud.2007.02.007, http://www.sciencedirect.com/science/article/pii/S0142694X07000191, participatory Design

6. Constantin, A., Johnson, H., Smith, E., Lengyel, D., Brosnan, M.: Designing computer-based rewards with and for children with autism spectrum disorder and/or intellectual disability. Computers in Human Behavior 75, 404 - 414 (2017). https://doi.org/https://doi.org/10.1016/j.chb.2017.05.030, http://www.sciencedirect.com/science/article/pii/S0747563217303515

7. Druin, A.: Cooperative Inquiry: Developing new technologies for children with children. In: Proceedings of ACM CHI 99 Conference on Human Factors in Computing Systems. vol. 14, pp. 223-230. ACM, Pittsburgh, PA, USA (1999), http://dl.acm.org/citation.cfm?id=303166

8. Druin, A.: Inclusive ownership of participatory learning. Instructional Science 42(1), 123-126 (2014)

9. Ehn, P.: Work-Oriented Design of Computer Artefacts. Ph.D. thesis, Stockholm, Sweden (1988) 
10. Fails, J.A., Guha, M.L., Druin, A.: Methods and techniques for involving children in the design of new technology for children. Foundations and Trends in HumanComputer Interaction 6(2), 85-166 (2013). https://doi.org/10.1561/1100000018, http://dx.doi.org/10.1561/1100000018

11. Frauenberger, C., Good, J., Fitzpatrick, G., Iversen, O.S.: In pursuit of rigour and accountability in participatory design. International Journal of Human-Computer Studies 74, 93-106 (2015)

12. Frauenberger, C., Good, J., Keay-Bright, W.: Designing technology for children with special needs: Bridging perspectives through participatory design. CoDesign 7(1), 1-28 (2011). https://doi.org/10.1080/15710882.2011.587013, https://doi.org/10.1080/15710882.2011.587013

13. Frauenberger, C., Good, J., Keay-Bright, W., Pain, H.: Interpreting input from children: A designerly approach. In: Proceedings of the SIGCHI Conference on Human Factors in Computing Systems. pp. 2377-2386. ACM (2012)

14. Guha, M.L., Druin, A., Fails, J.A.: Designing with and for children with special needs: An inclusionary model. In: Proceedings of the 7th International Conference on Interaction Design and Children. pp. 61-64. IDC '08, ACM, New York, NY, USA (2008). https://doi.org/10.1145/1463689.1463719, http://doi.acm.org/10.1145/1463689.1463719

15. Guha, M.L., Druin, A., Fails, J.A.: Investigating the impact of design processes on children. In: Proceedings of the 9th International Conference on Interaction Design and Children. pp. 198-201. ACM (2010)

16. Hornof, A.J.: Designing with children with severe motor impairments. In: Proceedings of the SIGCHI Conference on Human Factors in Computing Systems. pp. 2177-2180. CHI '09, ACM, New York, NY, USA (2009). https://doi.org/10.1145/1518701.1519032, http://doi.acm.org/10.1145/1518701.1519032

17. Korte, J., Potter, L.E., Nielsen, S.: How design involvement impacts deaf children. In: 2017 International Conference on Research and Innovation in Information Systems (ICRIIS). pp. 1-6 (July 2017). https://doi.org/10.1109/ICRIIS.2017.8002527

18. Korte, J., Potter, L.E., Nielsen, S.: The impacts of deaf culture on designing with deaf children. In: Proceedings of the 29th Australian Conference on Computer-Human Interaction. pp. 135-142. OZCHI '17, ACM, New York, NY, USA (2017). https://doi.org/10.1145/3152771.3152786, http://doi.acm.org/10.1145/3152771.3152786

19. Light, A., Akama, Y.: Structuring future social relations: The politics of care in participatory practice. In: Proceedings of the 13th Participatory Design Conference: Research Papers-Volume 1. pp. 151-160. ACM (2014)

20. Macaulay, A.C., Commanda, L.E., Freeman, W.L., Gibson, N., McCabe, M.L., Robbins, C.M., Twohig, P.L.: Participatory research maximises community and lay involvement. BMJ 319(7212), 774-778 (1999). https://doi.org/10.1136/bmj.319.7212.774, https://www.bmj.com/content/319/7212/774

21. Malinverni, L., Mora-Guiard, J., Padillo, V., Mairena, M., Hervás, A., Pares, N.: Participatory design strategies to enhance the creative contribution of children with special needs. In: Proceedings of the 2014 Conference on Interaction Design and Children. pp. 85-94. IDC '14, ACM, New York, NY, USA (2014). https://doi.org/10.1145/2593968.2593981, http://doi.acm.org/10.1145/2593968.2593981 
22. Newell, A.F., Morgan, M.E., Gibson, L., Forbes, P.: Experiences with professional theatre for awareness raising. Interacting with Computers 23(6), 594-603 (Nov 2011). https://doi.org/10.1016/j.intcom.2011.08.002, https://doi.org/10.1016/j.intcom.2011.08.002

23. Östlund, B., Olander, E., Jonsson, O., Frennert, S.: STS-inspired design to meet the challenges of modern aging. Welfare technology as a tool to promote user driven innovations or another way to keep older users hostage? Technological Forecasting and Social Change 93, 82-90 (2015)

24. Potter, L.E., Korte, J., Nielsen, S.: Design with the deaf: Do deaf children need their own approach when designing technology? In: Proceedings of the 2014 Conference on Interaction Design and Children. pp. 249-252. IDC '14, ACM, New York, NY, USA (2014). https://doi.org/10.1145/2593968.2610464, http://doi.acm.org/10.1145/2593968.2610464

25. Richards, O.K.: Exploring the empowerment of older adult creative groups using maker technology. In: Proceedings of the 2017 CHI Conference Extended Abstracts on Human Factors in Computing Systems. pp. 166-171. ACM (2017)

26. Rodgers, P.A.: Co-designing with people living with dementia. CoDesign 14(3), 188-202 (2018). https://doi.org/10.1080/15710882.2017.1282527, https://www.tandfonline.com/doi/full/10.1080/15710882.2017.1282527

27. Uzor, S., Baillie, L., Skelton, D.: Senior designers: Empowering seniors to design enjoyable falls rehabilitation tools. In: Proceedings of the SIGCHI Conference on Human Factors in Computing Systems. pp. 1179-1188. CHI '12, ACM, New York, NY, USA (2012). https://doi.org/10.1145/2207676.2208568, http://doi.acm.org/10.1145/2207676.2208568

28. Van Dijk, J., Hendriks, N., Frauenberger, C., Verhoeven, F., Slegers, K., Brandt, E., Branco, R.M.: Empowering people with impairments: How participatory methods can inform the design of empowering artifacts. In: Proceedings of the 14th Participatory Design Conference: Short Papers, Interactive Exhibitions, WorkshopsVolume 2. pp. 121-122. ACM (2016)

29. Vines, J., Clarke, R., Leong, T., McCarthy, J., Iversen, O.S., Wright, P., Olivier, P.: Invited sig - participation and hci: Why involve people in design? In: CHI '12 Extended Abstracts on Human Factors in Computing Systems. pp. 1217-1220. CHI EA '12, ACM, New York, NY, USA (2012). https://doi.org/10.1145/2212776.2212427, http://doi.acm.org/10.1145/2212776.2212427

30. Vines, J., Clarke, R., Wright, P., Iversen, O.S., Leong, T.W., McCarthy, J., Patrick: Summary report on CHI 2012 invited SIG: Participation and HCI: Why involve people in design? Tech. rep., CHI (2012)

31. Vines, J., Clarke, R., Wright, P., McCarthy, J., Olivier, P.: Configuring participation: On how we involve people in design. In: Proceedings of the SIGCHI Conference on Human Factors in Computing Systems. pp. 429-438. ACM (2013)

32. Williams, M.A., Buehler, E., Hurst, A., Kane, S.K.: What not to wearable: Using participatory workshops to explore wearable device form factors for blind users. In: Proceedings of the 12th Web for All Conference. pp. 31:1-31:4. W4A '15, ACM, New York, NY, USA (2015). https://doi.org/10.1145/2745555.2746664, http://doi.acm.org/10.1145/2745555.2746664 


\section{Workshop Proposal}

We propose a one-day workshop for 6-20 participants, in which PD researchers with experience working with a "fringe" group will reflect on the group's needs/abilities and any PD approaches they used. Created or adapted PD approaches for working with particular "fringe" groups will be shared and used as a starting point for adaptation to other, more or less similar, "fringe" groups.

\subsection{Workshop Organisation}

1. A subset of workshop participants who have created or adapted PD methods, tools or techniques to a particular "fringe" group ("creators") will pitch their approaches ("base approaches"), describing the context of use, procedures of use, results, challenges, lessons learned, and decisions made to support that "fringe" group.

2. Reflective brainstorming (whole group) will identify the needs/abilities of particular "fringe" groups, based on researchers' experiences of PD with them.

3. The organisers will run a "match-making" activity, to divide participants into subgroups based on similarities of their experiences working with "fringe" groups to the target groups of base approaches.

4. The organisers and creators of base approaches will facilitate group PD activities to:

(a) Identify commonalities and differences between new "fringe" groups and those targeted by base approaches

(b) Adapt base approaches to new "fringe" groups and new contexts

(c) Document novel PD approaches for specific "fringe" groups

(d) Present findings and discussion to the whole group

5. Subgroups will rotate to participants with experiences of "fringe" groups with greater differences from base approaches. PD activities will be repeated, with both base approaches and first novel approaches from which to adapt.

6 . The whole group will reflect on motivations for creating/adapting approaches, and feasibility of "borrowing" from approaches intended for other groups.

It is expected that this process will take a full day, with coffee and lunch breaks after activities 2, 4 and 5 .

\subsection{Pre-Workshop Plans}

Multiple recruitment approaches will be used to attract academic participants who have experience with and insight into PD with "fringe" groups, including:

- organisers' professional networks via word-of-mouth, as all organisers have experience with PD and strong professional networks;

- research and professional email lists to which several organisers have access (e.g. University of Edinburgh's CISA HCI group, Center for Participatory IT (PIT) at Aarhus University, PDworld and NordiCHI);

- social media channels (e.g. Twitter, Academic Facebook groups)

- this workshop's website: www.pushing-boundaries-pd-fringe-groups.inf.ed.ac.uk 